\title{
Technology Adoption in Education: A Systematic Literature Review
}

\author{
Kayode Emmanuel Oyetade*, Tranos Zuva, Anneke Harmse
}

Vaal University of Technology, ICT, 1930, South Africa

\begin{tabular}{l} 
A R T I C L E I N F O \\
\hline Article history: \\
Received: 11 August, 2020 \\
Accepted: 09 September, 2020 \\
Online: 08 November, 2020 \\
\hline Keywords: \\
Technology Adoption \\
Systematic Literature Review \\
Education \\
M-Learning \\
E-Learning \\
COVID-19
\end{tabular}

\section{Introduction}

Technology adoption is the choice of an individual to acquire and use an innovation. Technology is advancing faster today than ever before with developments such as cloud computing, robotics, Internet of Things (IoT), Artificial Intelligence (AI), Machine Learning (ML), etc., opening fresh opportunities for value creation and contributing to our life experiences. There is a consensus in both industry and academia on the growing importance of technology as a robust means for survival in today's fast-paced and knowledge-driven world [1]. Evidence abound of its success and impact on teaching and learning via documented research studies [2-4].

Moreover, adopting or rejecting a new technology is based on an individual's perception of the benefits of using the tool to achieve a goal $[5,6]$. Although technologies are advancing, the decision not to adopt has been categorised by poor innovation implementation, high cost, high failure rates, maintenance, poor technological planning, inadequate stakeholder participation [6-8].

\footnotetext{
*Corresponding Author: Kayode Emmanuel Oyetade, VUT, +27846514453 \&
} kayoyetade@gmail.com

www.astesj.com

https://dx.doi.org/10.25046/aj050611
An understanding of the factors affecting an individual's choice to adopt technology is essential both for stakeholders using these technologies as well as creators and producers of such technologies. Several theories and models exist to allow us understand the acceptance or rejection of a technology by an individual: This includes but not limited to Technology Adoption Model (TAM), Innovation Diffusion Theory (IDT), Unified Theory of Acceptance and Use of Technology (UTAUT), etc. [9].

The present research aims to fulfil the objective: To provide a summary of studies to determine the level of technology adoption in an academic setting. On this basis, a systematic literature review approach was employed to achieve this objective. Google Scholar and IEEE databases were searched using the keyword 'technology adoption and education or learning'. One hundred and thirty-two articles were initially obtained from the search. Inclusion and exclusion criteria were applied which reduced the list to 17 articles. These 17 articles were further analysed to fulfil the purpose of this research.

The next section presents the research method for this study. The result section provides the outcome of the literature review 
and the analysis of the selected literature. This is followed by the conclusion and possible area of future research.

\section{Methodology}

This section provides an overview of the research method used in the present research. The approach stipulated by [10] to conduct systematic literature was adopted.

\subsection{Data sources and selection criteria}

This paper reviews the adoption of various technology used in schools for teaching and learning. Therefore, the combination of the following keywords was applied: "Technology Adoption AND education OR learning". The title and abstract were checked for the occurrence of the keywords to ensure results are for articles focused on the study's research objective. English language was used to conduct this search to obtain a global perspective on the topic as well as avoid narrow searches. We limited our search to peer-reviewed texts available in online published journals and conference proceedings from Google Scholar and IEEE electronic databases.

The following inclusion criteria were deemed relevant for the present research:

- Studies on technology adoption application in education

- Studies that engage in any kind of technologies to support learning

- Studies written in English

The following exclusion criteria to remove articles not deemed fit for the current study:

- Studies that are not published as peer-reviewed journal articles and conference papers

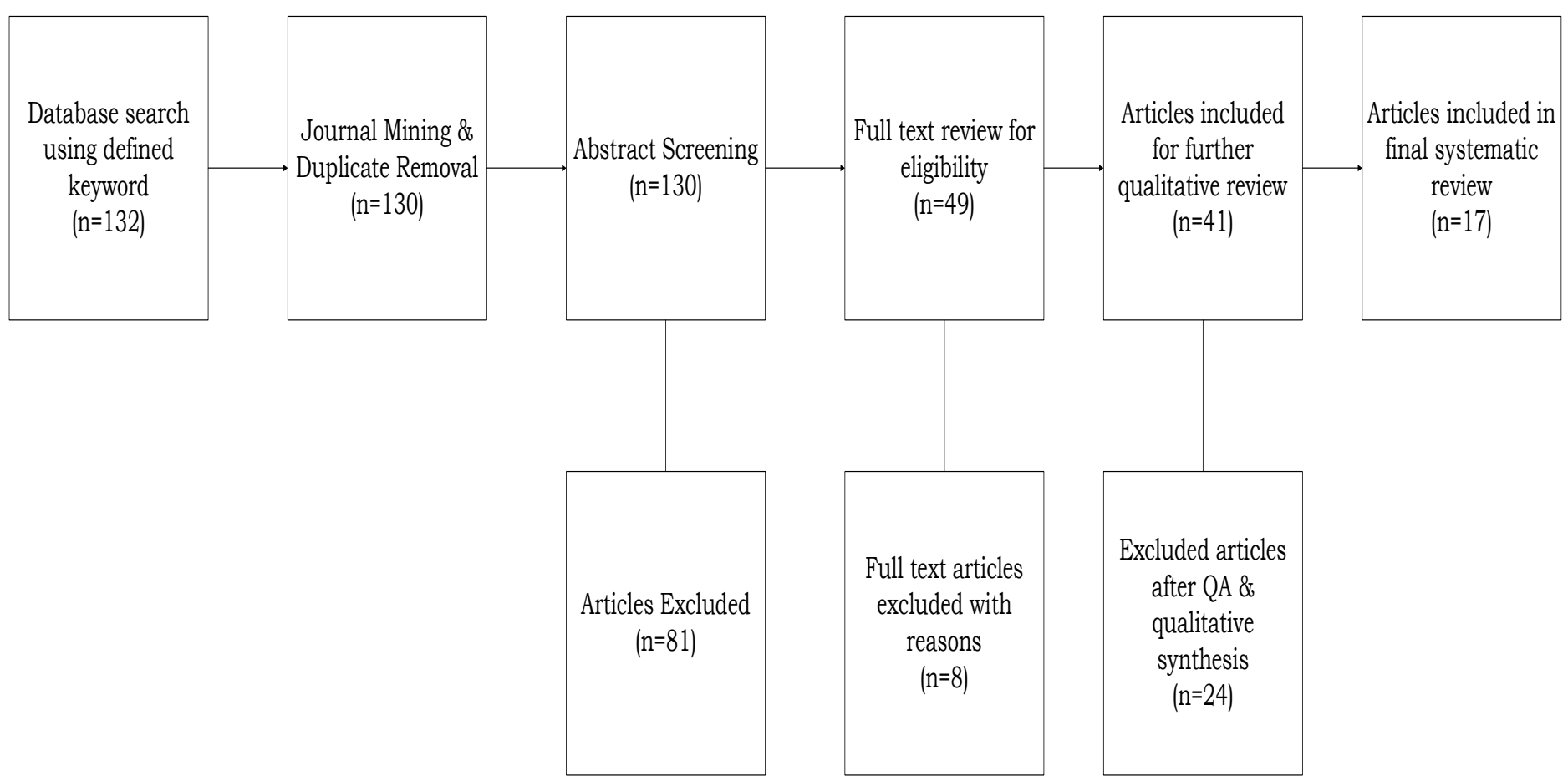

- Studies not originally written in English language

- Studies discussing technology adoption but not with an educational focus.

\section{Result}

As presented in Figure 1, the search and refinement process followed six steps.

Step 1: Database search was conducted using the abovementioned keywords. A total of 132 articles was realised. Step 2 focused on the application of the selection criteria by checking to remove duplicates due to the search using dual databases resulting in 130 articles. Step 3 reviewed the abstract to determine whether the article focused on the study's research objective and relevance to technology adoption. This allowed the study to remove 81 articles and left with 49 articles.

In step 4, full-text review was done on the 49 literatures for eligibility to provide a clear understanding of the research objectives. This allowed the study to exclude 8 articles which do not fit with reason resulting in 41 articles. Further qualitative review for quality assurance to ensure appropriateness and relevance to the research study was applied on these 41 articles. This allowed this study to arrive at a final list of 17 articles to be considered for review.

\subsection{Review of the Selected Literature}

One of the well-known success areas of technology adoption is the usage of m-learning in education. One of the motivations is the provision and easy access to learning content [11].
- Studies whose full text is not available online and

Figure 1: Steps to selection criteria and final outcome 
A study by [12] used TAM to analyse factors that influence learner's technology adoption. They found that the factors economics, usefulness, suitability, ease of use, enjoyment, and social influence impact learners' adoption of m-learning to facilitate and promote learning. Likewise, [13] explored the capacity and acceptance of mobile instant messaging, an $\mathrm{m}$ learning platform to increase student performance. They suggest that device portability, communication cost, collective capabilities, and learner control of the device are key factors of flexible learning in digital environments.

Evaluating the factors and effectiveness of e-learning adoption on student learning, [14] adopted the Interactivity Distance Education Web Learning (IDEWL), an enhanced online course creative and conferencing tool that integrates other add-on tools like online survey and e-blackboard for their study. There survey found e-learning effective with the enhancement of the interactivity modules in the students learning process.

On the other hand, [15] reported that the compulsory usage factor is essential for overall adoption of the e-learning system (ELS), either in a compulsory or voluntary setting. This is due to its effectiveness in promoting ELS as a core learning platform for students as well as discourage them from using other means to receive an education.

Similarly, [16] measured the factors that affect learners' adoption of blended ELS (BELS) and the perceived satisfaction of BELS according to their learning styles and gender differences. They report learning style did influence adoption of technology to provide flexible learning and improve understanding. In another related study, [17] examined the relationship between student's learning satisfaction and their use of video in a Moodle environment. He found that the use of video significantly impacted student's learning performance and satisfaction.

In answering student's willingness to learn using e-learning, [18] opines that designers of e-learning sites must ensure ease of navigating the web interface during the learning process. This designers must also ensure the quality of contents uploaded on the websites to enhance students learning while exploring college students learning attitudes with respect to their adoption of English e-tutoring websites. Using TAM as a theoretical framework for their study. There result showed that most users of English etutoring sites found online sources more effective and offer greater ease than traditional resources.

Furthermore, [19] conducted a study to examine key factors influencing the adoption of iPads using factors from extended TAM to design and deliver course content by academics. They found that University academics found iPads useful and easy to use with a high level of compatibility with their work.

Using the tablet devices in the classrooms, [20] reports that tablets impacts teaching and learning practices. This tablet devices provides a shift from the traditional way students learn to the media-rich and interactive environments. They therefore recommend stakeholders introduce educational and technical support to assist both educators' and learners' understanding of the benefit of these technologies in education.

Despite the growth and positive outcomes of technology adoption in education, [21] found that males and females do not differ in their belief about the usefulness of e-books. Usage of ebook in South African higher education corresponds to the effort and the external pressure exerted on students to promote the acceptance of e-books.

On mobile technology adoption for learning, [22] explored the correlation between students' ICT skills and factors that impact mobile technology adoption using the TAM framework. They found that basic and advanced ICT skills in mobile technology both played important roles in the intention to adopt m-learning.

Using mobile technology to enhance the convenience of teaching the English Language in Taiwan, [23] extended the factors of TAM to explain factors that affect the adoption of PDA. There result showed that extended TAM was effective in predicting and explaining the acceptance of English mobile learning.

To facilitate teaching and learning processes using the Learning Management Systems (LMSs) by University staffs, [24] used TAM extensions to identify factors that influence LMS usage behaviour and their underlying causal relationships. The analysis of data reveal that the proposed factors were significant predictors of faculty staff attitude towards LMSs. This confirms the validity of the extended TAM in determining users' technology acceptance.

In testing the effectiveness of a Blackboard $(\mathrm{Bb})$ course management system (CMS), [25] used an experimental and control group to conduct his test on English writing instruction in and outside of the $\mathrm{Bb}$ environment. The experimental group achieved encouraging results than the control group thereby contributing to learning English writing using $\mathrm{Bb}$. They also identified attitude, perceived usefulness, perceived ease of use, and technical support affect the adoption of CMS.

In [26], authors studied the effect of experience on students' intention to adopt webcast and found that students with previous experience in educational webcasts are most likely to adopt webcast. Ease of use and usefulness were found to be important factors in determining students' BI to use webcasts for learning purposes. They recommended that Webcast developers should pay attention to learners' intrinsic motivations and make them feel comfortable when using the environment for learning.

In conclusion, [27] extended the TAM model to explain the adoption and usage behaviour of social media users in higher education. It was found that subjective norm, perceived usefulness, perceived playfulness (happiness), and perceived ease of use strongly predict students' social media usage behaviour. Their findings suggest that social media use in classrooms should continue in higher institutions. This is because the intention to use translate to the actual use of this ICT tools.

The above review shows technology adoption has the potential to be used as an effective educational platform either directly or as an alternative tool for teaching and learning process.

\section{Results of the Review}

From the 17 articles examined, this section presents other findings from the above review and discusses the outcomes of the issues related to technology adoption as follows: 


\subsection{Publication History and Frequency}

Figure 2 shows the history and frequency of the identified articles selected for review. We observe the number of articles remains reasonably constant (2006-2012) with a noticeable peak in 2015. The low volume of publications between 2016 and 2019 could be related to our exclusion criteria which may have led to the omission of recent literatures. However, the existence of up-todate papers lends itself to continuing research efforts and trends of technology adoption in education.

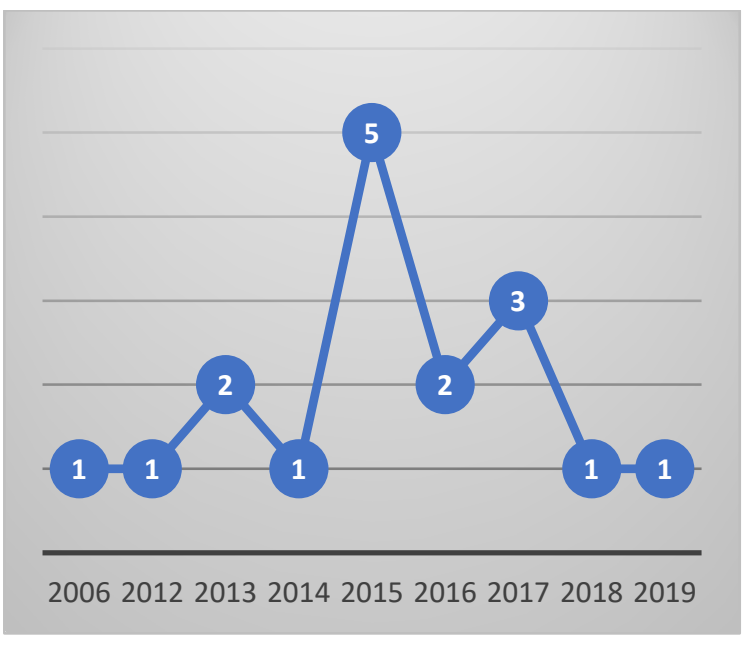

Figure 2: Publication History and Frequency

\subsection{Publication Type}

From the review of identified literature, Figure 3 presents the result of the articles reviewed by the publication type. It was observed that most of the articles ( $88 \%, 15$ articles) were obtained from published journals and the remainder $(12 \%, 2$ articles) are conference proceedings. The different sources of articles for the current research eliminate possible publication bias.

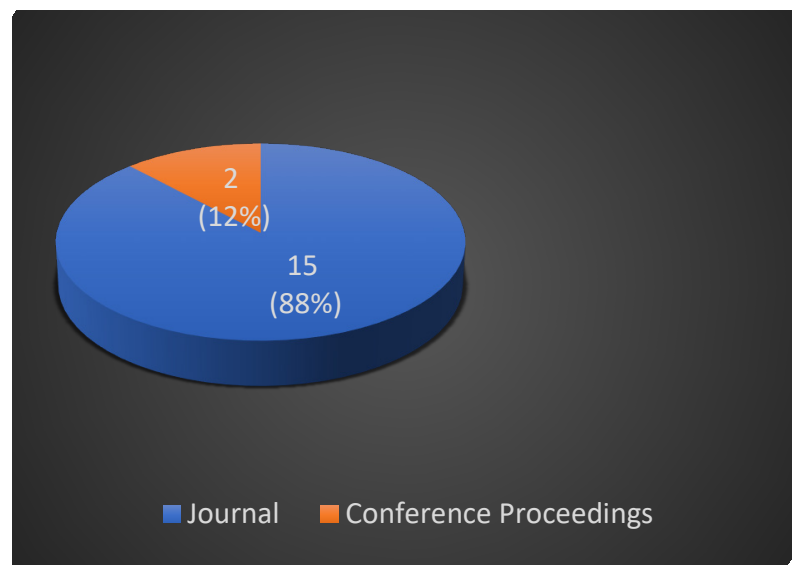

Figure 3: Publication Type

\subsection{Word Cloud of technology adoption tools}

As evidenced by the articles reviewed, Figure 4 shows the various technology adoption tools adopted for teaching and learning in education. M-learning and e-learning are mostly used technology. Other tools are classified into these two categories.

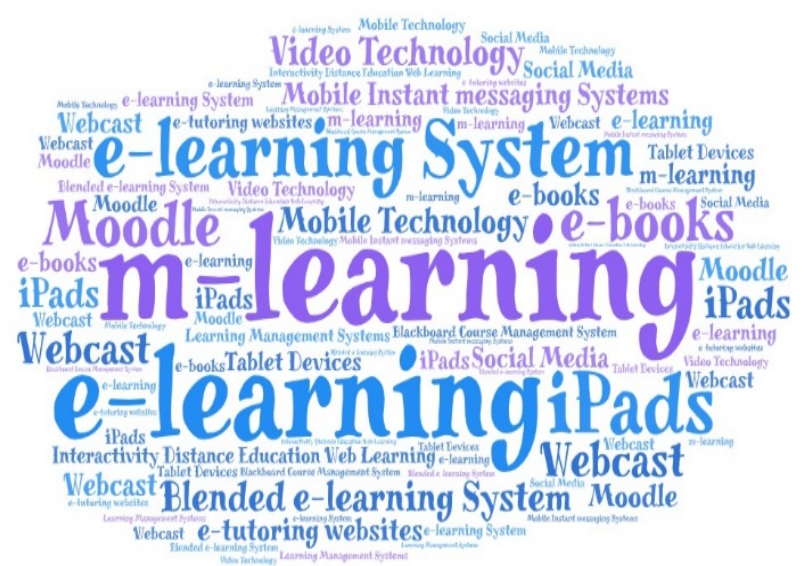

Figure 4: Word Cloud of Technology Adoption Tools

Even though, this research followed the steps for conducting a systematic review as specified by [10], it is not without limitations. For instance, the review results are limited to the search keywords used, and thus some studies may not have been included. However, we attempted to compensate for this by also relying on related recent literature reviews.

\section{Future Research}

Future research will investigate areas that can be expanded and improved on to increase the predictive performance of the Technology Adoption in education to support student's academic achievements.

\section{Conclusion}

The potential of technology has been identified in the above reviewed literature [14-17]. However, these technologies were blended with face to face interactions [25]. With the recent wave of the COVID-19 pandemic and the closure of schools, many schools were forced to seek alternative and virtual means of keeping the curriculum going using appropriate and connective technologies. This implies that technology adoption will gradually become a new normal in education as countries are gradually opening economic and academic activities that were affected by the COVID-19 pandemic.

Although a range of technologies is used in education, elearning and m-learning are the major tools adopted by many institutions to enhance teaching and learning as identified in the reviewed literature. However, despite the usage of technology adoption as reported in this study, [28-29] reports present findings on the challenges faced with the adoption of technologies as related to COVID-19. This includes affordability and availability of connectivity to the internet to access academic resources while most educators lack the technical support needed to use this ICTs.

The current study implemented a systematic literature review approach to provide a general picture of the usage of technology in education. Google scholar and IEEE databases were searched for articles published in online journals or conference proceedings from 2006 to 2019. The keyword Technology Adoption AND 
education OR learning was which resulted in an outcome of 132 articles. This was reduced to 17 articles for in-depth analysis using defined selection criteria. The researchers specifically conducted an analysis of contributions considering the research objectives that covered the year of publication, publication type, technology adoption platforms employed in the research study.

The findings highlight that technology is a relevant tool in schools to deliver the learning needs of $21^{\text {st }}$ century students as learners prepare to return to schools with the lifting of barriers to academic activities. It is believed that the current COVID-19 challenge will change academic curricula and lead to the prevalent usage of technology in the future.

\section{Conflict of Interest}

The authors declare no conflict of interest.

\section{Acknowledgment}

The present research has been prepared by Kayode Emmanuel under the supervision of Dr Anneke Harmse and Prof Tranos Zuva and supported by the Department of ICT at the Vaal University of Technology, Vaal, South Africa.

\section{References}

[1] A. Hidalgo, J. Albors, "Innovation management techniques and tools: a review from theory and practice," R\&d Management 38, 113-127, 2008, doi:10.1111/j.1467-9310.2008.00503.x.

[2] A. R. A. Arokiasamy, "A systematic review approach of mobile technology adoption in higher education,". Economics, Management Sustainability 2, 4855, 2017, doi:10.14254/jems.2017.2-2.5

[3] R. Scherer, F. Siddiq, J. Tondeur, "The technology acceptance model (TAM): A meta-analytic structural equation modelling approach to explaining teachers' adoption of digital technology in education", Computers Education 128, 13-35, 2019, doi:10.1016/j.compedu.2018.09.009.

[4] K. E. Oyetade, A. Harmse, T. Zuva, "Technology adoption factors in education: A review," in 2020 International Conference on Artificial Intelligence, Big Data, Computing and Data Communication Systems, (IEEE, Durban, 2020, doi:10.1109/icABCD49160.2020.9183830.

[5] M. C. M. O. Nemoto, E. P. G. d. Vasconcellos, R. Nelson, "The adoption of new technology: conceptual model and application,". Journal of technology management innovation 5, 95-107, 2010, doi: 10.4067/S071827242010000400008 .

[6] C. Plewa, I. Troshani, A. Francis, G. Rampersad, "Technology adoption and performance impact in innovation domains," Industrial Management \& Data Systems 112, 748 - 765, 2012, doi:10.1108/02635571211232316.

[7] E. D. Adamides, N. Karacapilidis, "Information technology support for the knowledge and social processes of innovation management," Technovation 26, 50-59, 2006, doi:10.1016/j.technovation.2004.07.019.

[8] L. Dooley, D. O'Sullivan, "Developing a software infrastructure to support systemic innovation through effective management," Technovation 23, 689704, 2003, doi:10.1016/S0166-4972(02)00020-2.

[9] K. E. Oyetade, T. Zuva, A. Harmse, "A review of the determinant factors of technology adoption" in Computer Science On-line Conference (Springer) 1226, 274-286, 2020, doi:10.1007/978-3-030-51974-2 26

[10] A. Siddaway, "What is a systematic literature review and how do I do one" University of Stirling 1, 1-13, 2014, Available online: https://pdfs. semanticscholar.org/2214/2c9cb17b4baab118767e497c93806d741461.pdf (accessed on 20 Sep. 20)

[11] S. Jeremy, K. E. Oyetade, K. G. Fomunyam, Operational Use of Mobile Learning: Understanding and Retention of Curriculum Content, Apple Academic Press, 2019, https://www.appleacademicpress.com/title.php?id=9781771887854.

[12] M. Sarrab, I. Al Shibli, N. Badursha, "An empirical study of factors driving the adoption of mobile learning in Omani higher education," International Review of Research in Open Distributed Learning, 17, 331-349, 2016, doi: 10.19173/irrodl.v17i4.2614

[13] A. Bere, P. Rambe, "An empirical analysis of the determinants of mobile instant messaging appropriation in university learning," Journal of
Computing in Higher Education, 28, 172-198, 2016. doi: 10.1007/s12528016-9112-2.

[14] A. T. Baharin, H. Lateh, S. S. Nathan, H. mohd Nawawi, "Evaluating effectiveness of IDEWL using technology acceptance model," in 2015 Procedia-Social Behavioral Sciences (Elsevier), 171, 897-904, 2015, doi: 10.1016/j.sbspro.2015.01.207.

[15] Y. C. Lee, "An empirical investigation into factors influencing the adoption of an e-learning system," Online information review, 2006, doi: $10.1108 / 14684520610706406$.

[16] A. Al-Azawei, P. Parslow, K. Lundqvist, "Investigating the effect of learning styles in a blended e-learning system: An extension of the technology acceptance model (TAM)," Australasian Journal of Educational Technology 33, 2017, doi: 10.14742/ajet.2758.

[17] J. T. Nagy, "Evaluation of online video usage and learning satisfaction: An extension of the technology acceptance model," International Review of Research in Open Distributed Learning, 19, 2018, doi 10.19173/irrodl.v19i1.2886.

[18] P. J. B. Tan, "An empirical study of how the learning attitudes of college students toward English e-tutoring websites affect site sustainability" Sustainability, 11, 1748, 2019, doi: 10.3390/su11061748

[19] M. S. Lane, A. Stagg, "University staff adoption of iPads: An empirical study using an extended TAM model," Australasian Journal of Information Systems 18, 2014, doi: 10.3127/ajis.v18i3.876.

[20] H. Montrieux, R. Vanderlinde, T. Schellens, L. De Marez, "Teaching and learning with mobile technology: A qualitative explorative study about the introduction of tablet devices in secondary education," PloS one, 10, 2015, doi: 10.1371/journal.pone.0144008.

[21] D. K. Maduku," Factors of E-book use intentions: Perspectives of students in a developing country," Perspectives on Global Development and Technology, 14, 597-618, doi:10.1163/15691497-12341364.

[22] K. Mac Callum, L. Jeffrey, "The influence of students' ICT skills and their adoption of mobile learning,". Australasian Journal of Educational Technology 29, 2013, doi: 10.14742/ajet.298.

[23] C.-C. Chang, C.-F. Yan, J.-S. Tseng, "Perceived convenience in an extended technology acceptance model: Mobile technology and English learning for college students," Australasian Journal of Educational Technology 28, 2012, doi: $10.14742 /$ ajet. 818

[24] N. Fathema, D. Shannon, M. Ross, "Expanding the Technology Acceptance Model (TAM) to examine faculty use of Learning Management Systems (LMSs) in higher education institutions," Journal of Online Learning Teaching, 11, 2015, https://jolt.merlot.org/Vol11no2/Fathema 0615.pdf.

[25] Y.-R. Tsai, "Applying the Technology Acceptance Model (TAM) to explore the effects of a course management system (CMS)-assisted EFL writing instruction," Calico Journal, 32, 153-171, 2015 , doi:10.1558/calico.v32i1.25961.

[26] M. N. Giannakos, P. Vlamos, "Educational webcasts' acceptance: Empirical examination and the role of experience," British Journal of Educational Technology, 44, 125-143, 2013, doi:10.1111/j.1467-8535.2011.01279.x.

[27] D. Z. Dumpit, C. J. Fernandez, "Analysis of the use of social media in Higher Education Institutions (HEIs) using the Technology Acceptance Model," International Journal of Educational Technology in Higher Education, 14, 5, 2017.

[28] T. E. Africa, "The Effect of Covid-19 on Education in Africa and its Implication for the Use of Technology," 1-81, 2020 doi:10.5281/zenodo.4018774.

[29] E. J. Sintema, "Effect of COVID-19 on the Performance of Grade 12 Students: Implications for STEM Education," EURASIA Journal of Mathematics, Science and Technology Education, 16, 1-6, 2020, doi $10.29333 /$ ejmste/7893. 